\title{
Value of serum magnesium estimation in diagnosing myocardial infarction and predicting dysrhythmias after coronary artery bypass grafting
}

\author{
RICHARD W BUNTON \\ From the Department of Cardiothoracic Surgery, University of Otago, Dunedin, New Zealand
}

ABSTRACT Serial serum magnesium estimations, beginning before operation, were performed on 200 patients who underwent coronary artery bypass grafting. The results indicate that serum magnesium concentration is of no value in the diagnosis of myocardial infarction in the postoperative patient or in predicting which patients are susceptible to postoperative dysrhythmias. There was no statistically significant difference in serum magnesium values between those patients who had an uncomplicated course and patients who had sustained either myocardial infarction or postoperative dysrhythmia or both.

Serum magnesium estimations have been used in the diagnosis of myocardial infarction occurring in patients admitted to coronary care units, with significant falls in serum magnesium concentration documented in those who have sustained an infarction $^{1}$ or in those whose infarction has been complicated by dysrhythmia or cardiac failure. ${ }^{23}$ In a small group of patients who had had coronary artery surgery serum magnesium estimations were found to be of no value in diagnosing perioperative myocardial infarction. ${ }^{4}$

The purpose of the present study was to determine the usefulness of serum magnesium estimations in diagnosing perioperative infarction and in identifying those at risk from developing postoperative dysrhythmias in a large group of patients after coronary artery bypass grafting.

\section{Patients and methods}

The case notes of 200 patients who had undergone coronary artery bypass grafting from February 1981 to October 1982 were retrospectively reviewed. There were 176 men and 24 women with an average age of 57 years. During this period there were six deaths, four within 24 hours of surgery. These six

Address for reprint requests: Dr RW Bunton, Department Cardiothoracic Surgery, Dunedin Public Hospital, PO Box 946, Dunedin, New Zealand.

Accepted 17 August 1983 patients were excluded as serial serum magnesium estimations were not available for these patients.

Particular note was taken of whether the patients were diabetic, taking digoxin before operation or in the perioperative period, or receiving antidysrhythmic drugs before operation. Those taking digoxin in the perioperative period received a total of $0.75 \mathrm{mg}$ over the 24 hours before the procedure and $0.25 \mathrm{mg}$ daily afterwards. Eighty nine per cent of the patients were having antidysrhythmic drugs before operation, most commonly beta blockers or calcium antagonists, which were used for treatment of angina.

Standard cardiopulmonary bypass techniques were used, with a Sarns portable roller pump for perfusion and a Rygg-Kyvsgaard oxygenator. Cold potassium cardioplegia was used for myocardial protection, the solution containing $1.5 \mathrm{mmol} / 1$ of magnesium. A total of $1000-1500 \mathrm{ml}$ of cardioplegic solution was used for each procedure.

Perioperative infarction was diagnosed when the creatinine phosphokinase exceeded 700 units in association with the appearance of new $Q$ waves of at least 0.04 seconds in duration on the electrocardiogram. The presence of only one of the above criteria in association with a suggestive clinical course was accepted as evidence of myocardial infarction. Dysrhythmias were considered significant when they required specific treatment.

The patients were subgrouped according to their postoperative course. There were four subgroups, 946 
consisting of $(a)$ those who had had an uncomplicated recovery, $(b)$ those who had sustained a perioperative myocardial infarction, $(c)$ those who had sustained both a perioperative infarction and a postoperative cardiac dysrhythmia, and $(d)$ those who had developed a postoperative cardiac dysrhythmia.

Serum magnesium estimations were carried out on the day of admission, twice during the procedure, and then daily for up to four days after operation. Serum magnesium was estimated by the atomic absorption method using an Instrument Laboratory aa/ae Spectrophotometer 751, normal values for the laboratory being $0 \cdot 7-1 \cdot 1 \mathrm{mmol} / \mathrm{l}$.

Data were statistically analysed by the paired and unpaired $t$ test.

\section{Results}

Table 1 shows the patient subgroups according to their postoperative course and table 2 the different dysrhythmias sustained in the postoperative period.

Figures 1-4 show the serum magnesium concentrations for the postoperative subgroups. In all subgroups serum magnesium fell significantly from the preoperative values, reaching the lowest value on the first postoperative day. In all cases these concentrations were significantly lower than the preoperative values $(p<0.001)$. From the first postoperative day the concentrations slowly rose and by the fourth day had returned to approximate preoperative values.

Table 1 Data on the 200 patients and their postoperative course

\begin{tabular}{ll}
\hline & No of patients \\
\hline Total (average age 57 y) & 200 \\
Male & 176 \\
Female & 24 \\
Postoperative course & \\
$\quad$ Uncomplicated & 112 \\
Infarction & 13 \\
Dysrhythmia and infarction & 21 \\
Dysrhythmia & 54 \\
\hline
\end{tabular}

Table 2 Types of dysrhythmia after coronary artery bypass grafting

\begin{tabular}{lc}
\hline & No of patients \\
\hline Atrial fibrillation & 36 \\
Ventricular tachycardia or fibrillation & \\
$\quad$ bigeminy & 9 \\
Sinus tachycardia & 6 \\
Nodal rhythm or heart block & 5 \\
Other & 2 \\
Total & $58^{*}$ \\
\hline
\end{tabular}

*Four patients had two different dysrhythmias.
When the uncomplicated group was compared with the other subgroups there was no significant difference (that is, with $p<0.05$ ) found at any of the sampling times. Although the serum magnesium concentrations in the infarct group tended to be lower than in the other groups on the second and third postoperative day, this tendency did not reach significance ( $p=0.12$ and 0.19 respectively).

The presence of digoxin or antidysrhythmic drugs did not affect the serum magnesium concentrations or the postoperative course.

\section{Discussion}

The trends in serum magnesium concentration during cardiopulmonary bypass have been described. ${ }^{5-7}$ Serum magnesium falls during perfusion and returns to normal at intervals varying from 12 hours $^{5}$ to two days ${ }^{7}$ and 12 days $^{6}$ after operation. In the present study serum magnesium fell during cardiopulmonary bypass but had returned to preoperative values by the fourth postoperative day. The reasons for the variability in the time required for serum magnesium to return to normal are not clear. Magnesium supplementation can accelerate the return to normal of serum values. ${ }^{6}$ Before operation cardiac patients tend to have serum magnesium concentrations that are at the lower end of normal ${ }^{5}$ and this tendency was seen in the present study. This may be related to long term diuretic treatment or the presence of cardiac failure. ${ }^{3}$

Serum magnesium concentrations have been used clinically in diagnosing uncomplicated myocardial infarction ${ }^{1}$ or infarction which has been complicated by dysrhythmia or cardiac failure. ${ }^{23}$ The present study confirms the findings of Forster $\mathrm{et} \mathrm{al}^{4}$ that the serum magnesium concentration is of no value for detecting perioperative myocardial infarction after coronary artery bypass surgery. The concentration tended to be lower in those patients who sustained a perioperative infarct than in those who had an uncomplicated course, but this tendency did not reach significance. Serum magnesium concentrations returned to preoperative values in these patients at the same time as in those who had uncomplicated courses. In those patients who had infarcts plus dysrhythmias serum magnesium concentrations did not differ statistically from the concentrations in those who had an uncomplicated course. Previously an association has been found between lower serum magnesium concentrations and dysrhythmias after myocardial infarction in medical patients. ${ }^{23}$ This was not found in the present surgical series.

The serum magnesium concentration of patients suffering from postoperative dysrhythmias did not differ significantly from that of patients who had an 


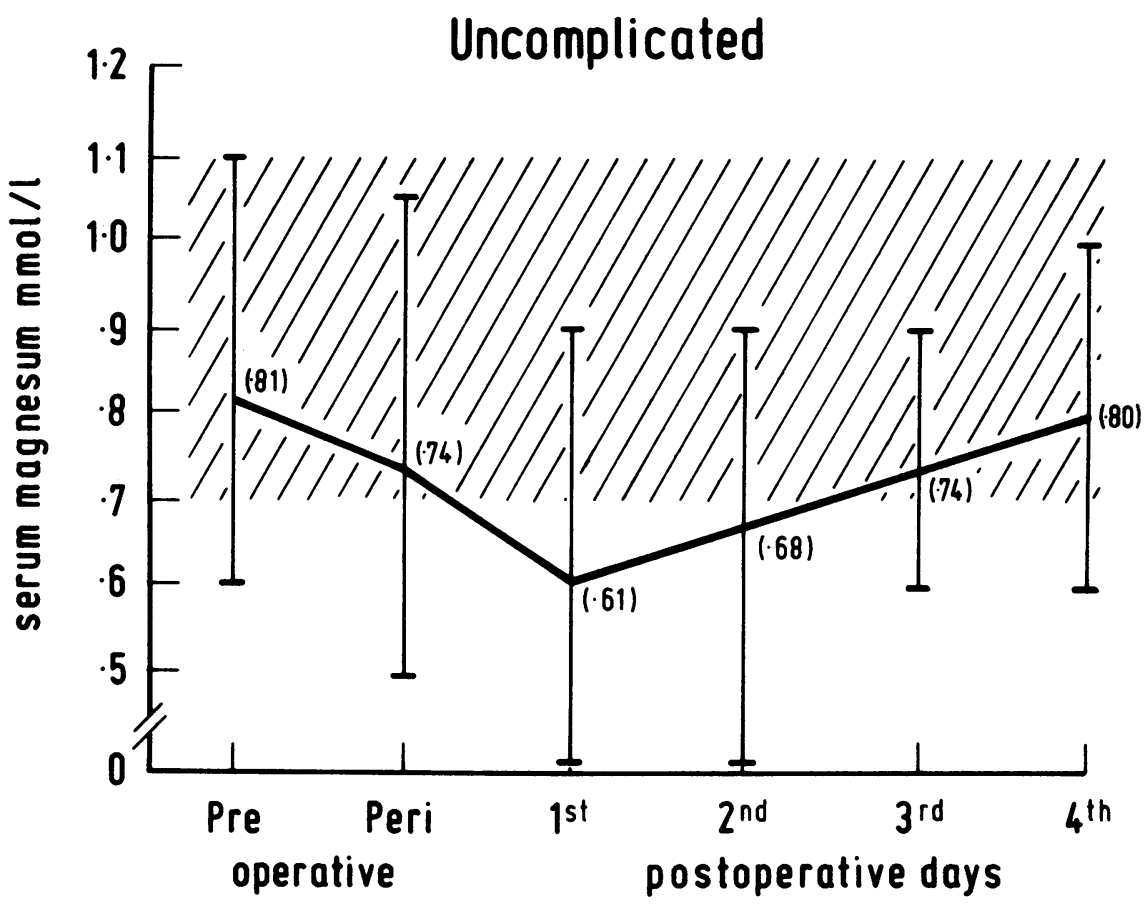

Fig 1 Serum magnesium values in 112 patients who had an uncomplicated course after coronary artery bypass surgery. Numbers in parentheses are means and vertical bars indicate ranges.

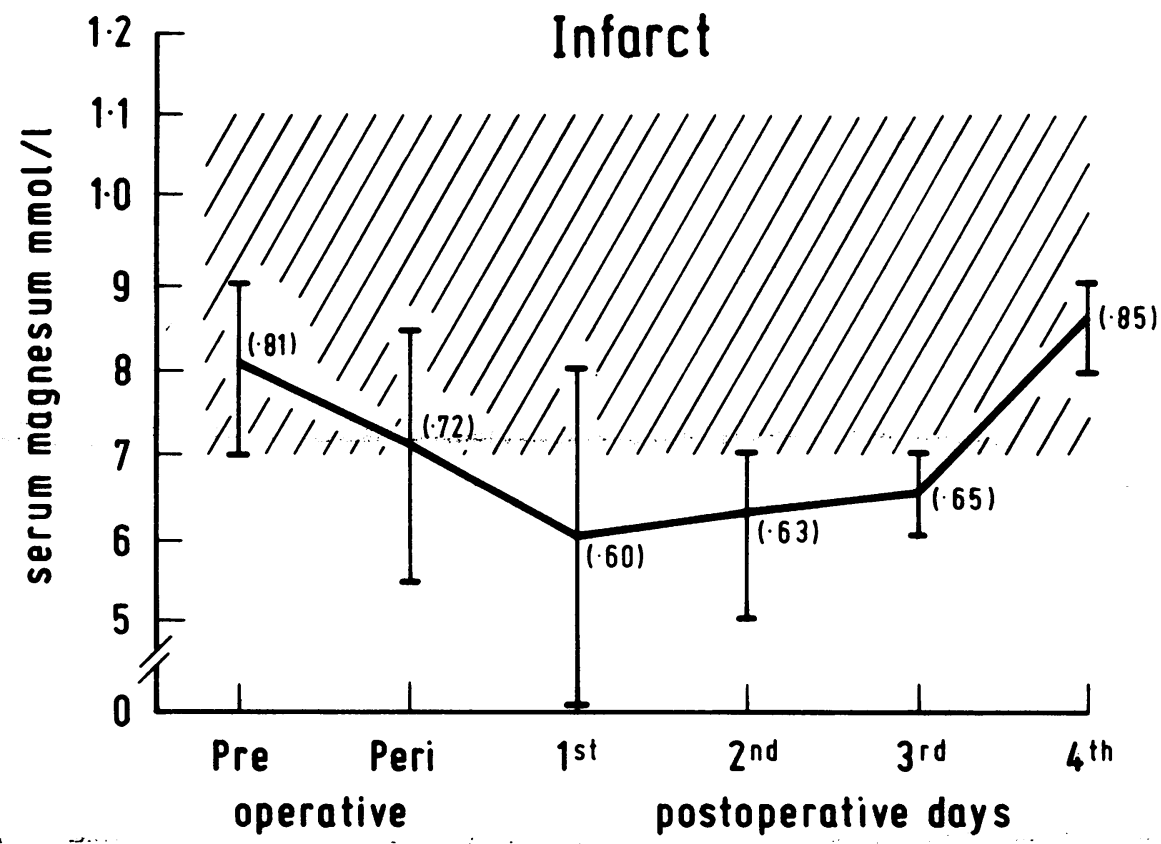

Fig 2 Serum magnesium values in 13 patients who sustained a perioperative myocardial infarction while undergoing coronary artery bypass surgery. 


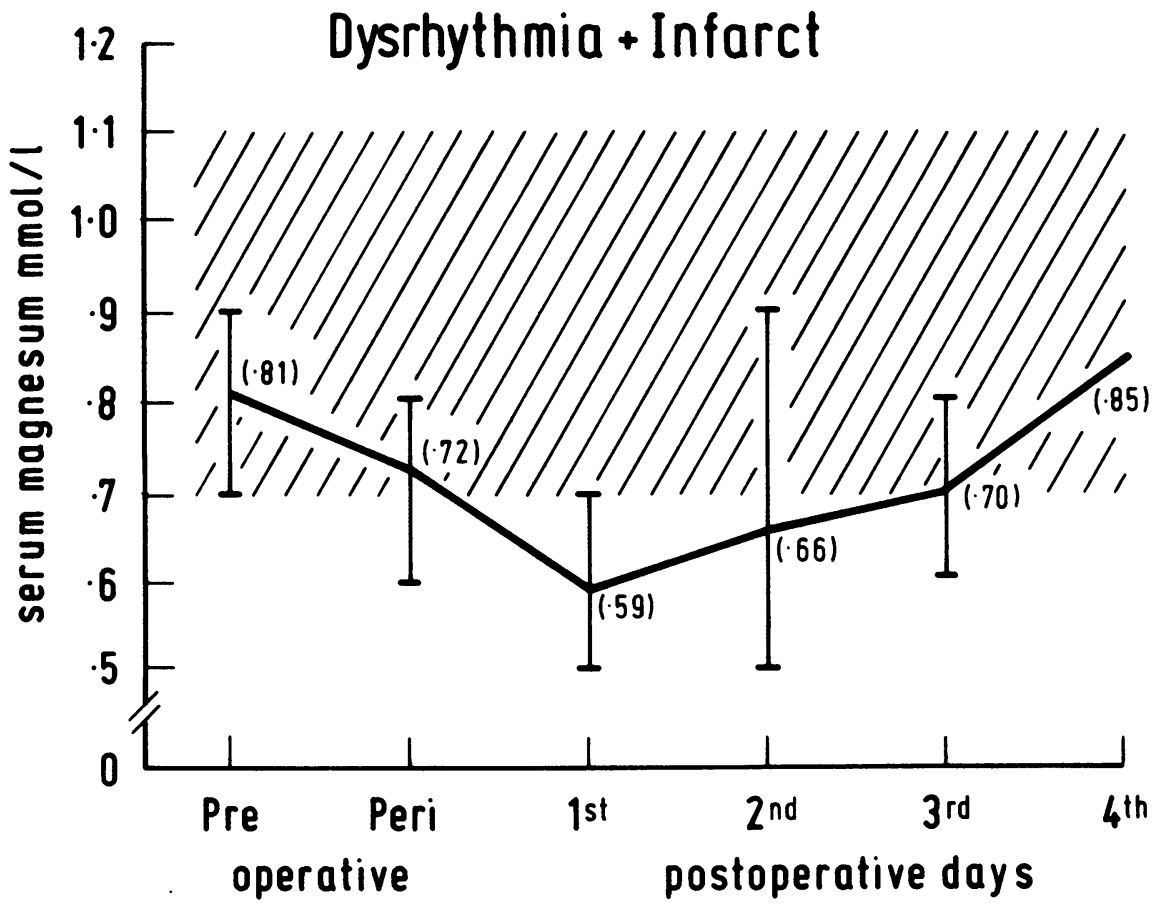

Fig 3 Serum magnesium values in 21 patients who sustained both a perioperative myocardial infarction and a postoperative dysrhythmia after coronary artery bypass surgery.

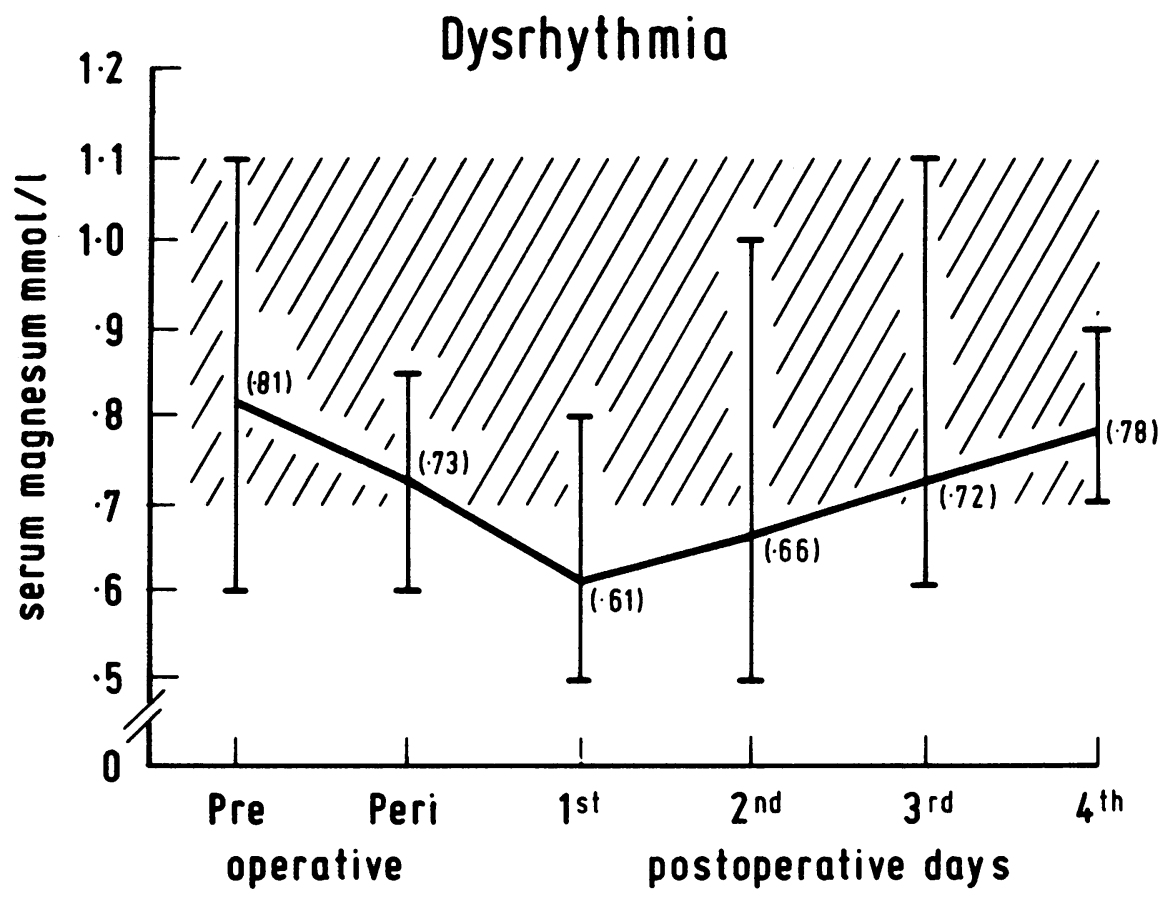

Fig 4 Serum magnesium values in 54 patients who sustained a postoperative dysrhythmia after coronary artery bypass surgery. 
uncomplicated postoperative recovery. When each dysrhythmia was individually analysed, again no significant difference was found between those who had an uncomplicated course and those who did not.

The present study has shown that routine serial serum magnesium estimations are of no value in diagnosing perioperative myocardial infarction or in predicting which patients are susceptible to postoperative dysrhythmias after coronary artery bypass grafting.

\section{References}

'Abraham AS, Eylath U, Weinstein M, Czaczkes E. Serum magnesium levels in patients with acute myocardial infarction. $N$ Engl J Med 1977;296:862-3.
${ }^{2}$ Dyckner T. Serum magnesium in acute myocardial infarction. Acta Med Scand 1980;207:59-66.

${ }^{3}$ Rector WG, De Wood MA, Williams RV, Sullivan JF. Serum magnesium and copper levels in myocardial infarction. Am J Med Sci 1981;281:25-9.

${ }^{4}$ Forster A, Stalder R, Bloch A, Suter P. The value of serum magnesium estimations in the diagnosis of acute perioperative myocardial infarction after coronary artery surgery. J Cardiovasc Surg 1981;22:1635.

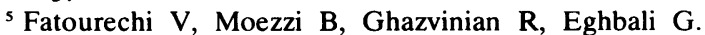
Plasma digoxin and magnesium concentration in open heart surgery. J Cardiovasc Surg 1979;20:151-8.

${ }^{6}$ Khan RMA, Hodge JS, Bassett HFM. Magnesium in open heart surgery. J Thorac Cardiovasc Surg 1973;66:185-91.

${ }^{7}$ Vejlsted $H$, Eliasen P. Postoperative serum level and urinary excretion of magnesium following heart surgery. Scand J Thorac Cardiovasc Surg 1978;12:91-4. 